\title{
O QUE PENSAM OS EGRESSOS SOBRE A SUA FORMAÇÃO INICIAL NA LICENCIATURA EM MATEMÁTICA?
}

\author{
Jane Mery Richter Voigt* \\ Marly Krüger de Pesce**
}

\begin{abstract}
Resumo: O objetivo deste texto é apresentar as percepções de professores egressos de um curso de Licenciatura em Matemática sobre a sua formação docente. $\mathrm{O}$ referencial teórico fundamenta-se em autores como Imbernón (2009), Tardif (2011), Gatti e Nunes (2009) e Fiorentini e Lorenzato (2006). De viés qualitativo, a pesquisa contou com 12 participantes, e como instrumento para coleta de dados utilizou-se um questionário com questões abertas e fechadas. Os resultados revelam aspectos importantes durante a formação inicial como: as condições institucionais como significativas para o desempenho e formação do licenciando ao longo do curso de formação; a articulação entre os conhecimentos específicos da área de formação e os pedagógicos como norteadores da formação; a aproximação com a escola de educação básica, o exemplo das práticas dos professores formadores e a troca de experiências com os colegas de curso como fundamental para a formação do professor.
\end{abstract}

Palavras-chave: Licenciatura em Matemática; Formação de professores; Práticas educativas.

\section{WHAT DO THE GRADUATES THINK ABOUT THEIR INITIAL EDUCATION IN MATHEMATICS DEGREE?}

\begin{abstract}
The objective of this text is to present the perception of graduated teachers of a degree course in Mathematics about their teacher education. The theoretical framework is based on authors such as Imbernón (2009), Tardif (2011), Gatti and Nunes (2009), Fiorentini and Lorenzato (2006). This research based on a qualitative approach had 12 participants and a questionnaire with open and closed questions was used as a tool for data collection. The results reveal important aspects of the initial training as: institutional conditions as significant for the performance and training of the students throughout the undergraduate course; the specific knowledge of the area of formation and the pedagogical knowledge as guides of the formation; the approach to basic education school, the example of the practices of the teacher trainers and the exchange of experiences with the colleagues of course as fundamental for the teacher education.
\end{abstract}

Keywords: Mathematics undergraduate course; teacher education; educative practice.

Submissão 20-07-18 Aceite 30-07-18

INTRODUÇÃO

A globalização, os avanços tecnológicos, as mudanças sociais e culturais implicam revisão de políticas educacionais, o que inclui políticas relacionadas à formação de professores. Em meio à complexidade da sociedade atual, para Hargreaves

\footnotetext{
* Pós-Doutoranda em Ciências da Educação na especialidade Desenvolvimento Curricular na Universidade do Minho - UMINHO, Braga, Portugal. É professora titular da Universidade da Região de Joinville-UNIVILLE, atuando no Programa de Pós-Graduação - Mestrado em Educação, em cursos de graduação e como pesquisadora e coordenadora do Grupo de Pesquisa Estudos Curriculares, Docência e Tecnologias - GECDOTE. Pesquisadora participante do Observatório do Ensino Médio Catarinense - OEMSC. Tem experiência na área de ensino de Matemática na educação básica e no ensino superior e na formação de professores. Desenvolve pesquisas envolvendo temas como: currículo, políticas curriculares, autonomia e flexibilidade curricular, práticas educativas na Educação Básica.

** Doutorado em Educação - Psicologia da Educação pela Pontifícia Universidade Católica de São Paulo - PUC SP. É professora titular do curso de Letras em disciplinas como Linguística Aplicada e Metodologia em Língua Estrangeira, Estágio e Análise do Discurso e professora colaboradora do mestrado de Educação da Univille. É coordenadora do subprojeto de Língua Portuguesa do Pibid/Univille e coordenadora da Unidade de Educação a Distância e do Centro de Inovação Pedagógica da Univille. Realiza pesquisas sobre formação e condições do trabalho docente, letramento, análise crítica do discurso, uso das tecnologias de informação e comunicação.
} 
(2003), a docência acaba se tornando uma profissão paradoxal. Para o autor, espera-se que os professores construam comunidades e aprendizagem, formem e preparem seus alunos para a sociedade do conhecimento, para que sejam inovadores, atuem com flexibilidade para atender às transformações econômicas atuais. Por outro lado, esperase que eles ajudem a minimizar o consumismo exacerbado, a reduzir os problemas gerados pela sociedade baseada no conhecimento e as desigualdades sociais.

Diante desse cenário, as políticas para a formação de professores promoveram diversas alterações na organização dos cursos de licenciatura, buscando romper com o paradigma de racionalidade técnica, presente nos cursos de formação docente. Dentre as mudanças, destacamos as Diretrizes Curriculares Nacionais para a Formação de Professores da Educação Básica (BRASIL, 2002a), que propuseram um novo perfil de egresso. Com essa política curricular, os cursos de licenciatura passaram a discutir e reformular seus projetos político-pedagógicos, estabelecendo uma matriz curricular que permitisse uma formação capaz de relacionar teoria e prática, articulando conhecimentos pedagógicos e específicos. Com as mudanças, as questões pedagógicas passaram a permear todo o curso, e não apenas os anos finais.

Em 2009, atenta às demandas sociais e políticas, a instituição na qual se realizou a presente pesquisa delineou um perfil profissiográfico comum a todos os cursos de licenciatura oferecidos por ela, utilizado em todos os Projetos Pedagógicos dos Cursos de Licenciatura, assumindo que os saberes docentes são a base na formação profissional em educação. A matriz de cada curso contemplou conteúdos específicos e conteúdos pedagógicos, assegurou o contato com a realidade escolar desde o início do curso e a reflexão sobre questões mais amplas da docência, incluindo seus aspectos políticos e sociais.

Com as mudanças propostas nos cursos de licenciatura, faz-se importante ressaltar que as concepções teórico-metodológicas que embasam os projetos pedagógicos de cursos de licenciatura são elementos que participam da constituição identitária do futuro professor. Para Marcelo (2009, p. 9), a formação docente está relacionada aos "processos usados pelos professores nas suas aprendizagens, processos esses que desenvolvem e melhoram o seu repertório de competências".

Com base nesses movimentos, nas mudanças apontadas e considerando a nossa vivência como professoras formadoras, especialmente no curso de licenciatura, surgem questões como: De que forma o curso de Licenciatura em Matemática contribui para a formação profissional dos estudantes? Quais as disciplinas ou conteúdos que mais 
contribuem na sua atuação profissional? A formação inicial traz subsídios suficientes para enfrentar os desafios da profissão? Ao falar em desafios da profissão, vale destacar que é na formação inicial que o professor constitui a sua profissionalidade. É nesse momento que o acadêmico traz suas crenças e as confronta teoricamente e em atividades práticas, atribuindo sentidos e significados do ser professor (ROLDÃO, 2006).

Com base nas questões levantadas, o objetivo deste artigo é apresentar as percepções de professores egressos de um curso de Licenciatura em Matemática em relação à sua formação docente inicial. Ouvir o que pensam os egressos sobre sua formação inicial representa uma possibilidade de compreender em que medida os conhecimentos aprendidos na graduação são efetivos para a prática docente. Para André (2010, p. 176), “investigar o que pensa, sente e faz o professor é muito importante, mas é preciso prosseguir nessa investigação, para relacionar essas opiniões e sentimentos aos seus processos de aprendizagem da docência e seus efeitos na sala de aula".

A pesquisa a que se refere o presente artigo foi realizada com egressos de um Curso de Licenciatura em Matemática de uma instituição de ensino superior de Santa Catarina. O instrumento de coleta de dados foi um questionário, com perguntas abertas e fechadas, organizado em duas categorias: a) a trajetória dos egressos no Curso de Licenciatura em Matemática; b) percepção dos egressos sobre a sua formação inicial. Participaram 12 egressos da Licenciatura em Matemática que estavam atuando como professores no momento da pesquisa.

Empregou-se questionário por ser uma das formas escritas mais empregadas em pesquisas. Ao usar questões do tipo fechada, obtiveram-se informações objetivas, que foram descritas e utilizadas ao longo da pesquisa na relação com outras informações. Já as questões abertas permitiram às pesquisadoras interpretar as expressões dos participantes e refletir com maior propriedade sobre as questões de pesquisa (GONZÁLEZ REY, 2005). Por ser uma pesquisa de viés qualitativo, entendemos que “é preciso que a análise não se restrinja ao que está explícito no material, mas procure ir mais a fundo, desvelando mensagens implícitas, dimensões contraditórias e temas sistematicamente 'silenciados"” (LÜDKE; ANDRÉ, 1986, p. 48). Nesse sentido, os resultados apresentados neste texto foram analisados considerando as contribuições de autores como Imbernón (2009), Tardif (2011), Gatti e Nunes (2009), Fiorentini e Lorenzato (2006), que perpassam o campo da formação de professores e da educação matemática. 


\section{ASPECTOS SOBRE A TRAJETÓRIA DE EGRESSOS NO CURSO DE LICENCIATURA EM MATEMÁTICA}

Os dados sobre a trajetória dos egressos participantes desta pesquisa foram obtidos por meio de questionário enviado a 55 professores de Matemática da rede pública estadual de ensino. Dentre os respondentes, foram selecionados 12 professores egressos do curso de licenciatura, lócus desta pesquisa, cuja formação contempla as mudanças ocorridas após as diretrizes propostas em 2002 e a reformulação proposta pela universidade formadora em 2009. Mesmo que a reforma das licenciaturas em questão aqui não seja recente, entendemos que, para compreender novas propostas de formação, precisamos realizar estudos que possam revelar como se deu a constituição dos professores, nesse caso os de Matemática. Assim, os dados da presente pesquisa podem servir de sustentação para novas instigações e/ou reformulação nos cursos de licenciatura.

O lócus da investigação é uma universidade comunitária que oferece cursos de graduação e de pós-graduação nas mais diversas áreas e atende toda a região norte de Santa Catarina. Nessa universidade, o curso de Licenciatura em Matemática prevê em seu Projeto Pedagógico o desenvolvimento de competências de comunicação, investigação, compreensão e da contextualização das ciências no âmbito sociocultural. Com base nas diretrizes curriculares propostas em 2002 (BRASIL, 2002b), a matriz curricular foi organizada em torno de três eixos: disciplinas da formação matemática, disciplinas de integração e as de formação pedagógica. A integração dos eixos é realizada pela disciplina Prática de Ensino da Matemática e pelo Estágio Curricular Supervisionado.

Pesquisas mostram que há pouco interesse dos egressos do ensino médio em frequentar cursos de licenciatura. Dos que optam pela licenciatura em Matemática, muitas vezes não atuam como professores; a escolha é feita pela afinidade com a área de conhecimento e com a docência. Isso pode ser observado na fala de Moreira et al. (2012, p. 22):

Observa-se uma recorrente citação/valorização de "gostar da matemática" como justificativa ou como um dos principais fatores que pesaram na escolha da licenciatura. Em certo sentido, parece que a profissão docente em si fica em segundo plano, quando se pensa no motor que leva à decisão pela licenciatura em Matemática, pois seria razoável imaginar que "gostar de matemática" levasse à escolha do bacharelado. 
A escolha pela docência pressupõe que os participantes desta pesquisa, ao optarem pelo curso de Licenciatura em Matemática, não apenas "gostam de matemática", como também "gostam de matemática e de ensinar matemática". Isso pode estar relacionado ao fato de os egressos, que atuavam como professores no momento da pesquisa, dizerem que foi ótimo ou bom o seu desempenho no curso. Dos resultados, oito (67\%) manifestam ter tido bom desempenho no curso e quatro (33\%) acham que foi ótimo. Não é possível avaliar os critérios que levaram o egresso a fazer tal avaliação; esta pode estar relacionada ao seu desempenho na escola como docente.

Ao serem indagados sobre a sua participação nas atividades de ensino, pesquisa e extensão na universidade, constatou-se que apenas dois (16,7\%) participaram de projetos de iniciação científica (Programa Institucional de Bolsas de Iniciação Científica - PIBIC) e seis (50\%), de projetos de extensão. Os resultados refletem uma realidade em que o acesso à participação em atividades de PIBIC e projetos de extensão universitária é muito restrito na instituição, pois há poucas vagas para os projetos submetidos a cada ano nos editais de demanda interna, e os de demanda externa, muitas vezes, não atendem às licenciaturas.

Conforme as diretrizes para os cursos de licenciatura (BRASIL, 2002a), o acadêmico deve cumprir uma carga horária destinada às atividades acadêmico-científico-culturais, que têm como objetivo enriquecer a sua formação. As atividades mais realizadas pelos participantes foram: reforço escolar nas escolas de educação básica da região (11 participantes, 91,7\%); participação em eventos científicos (100\% dos participantes). No que se refere aos eventos científicos, destaca-se o Encontro Regional de Estudantes de Matemática do Sul do Brasil (EREMATSUL), cujo acesso foi subsidiado pela instituição e teve como tema geral a Educação Matemática, além das semanas acadêmicas promovidas pelo curso de Matemática. As atividades relacionadas à participação em eventos científicos podem despertar ou ainda intensificar o interesse dos acadêmicos pela produção científica de sua área de atuação, incentivando-os à pesquisa, tanto na graduação como na sua futura prática docente.

Diante dos dados aqui citados, podemos pensar sobre o quanto a vivência, enquanto acadêmico, em diferentes âmbitos para além da sala de aula, como participação em eventos internos da instituição (semanas acadêmicas), grupos de estudo e troca de experiências, o constitui como professor. Dessa forma, as condições institucionais durante a formação são significativas para a formação do licenciado, 
oferecendo não só atividades de ensino, como também de pesquisa e extensão. Imbernón (2009) reforça essa ideia ao mencionar que a formação inicial não deve estar unicamente centrada nas disciplinas da matriz curricular, mas deve ser também elemento promotor de novas relações na prática de formação. Assim, as experiências adquiridas na participação nas demais atividades do curso podem permitir ao egresso perceber que ele também é construtor de conhecimento de forma individual ou coletiva.

Considerando os dados apresentados das atividades mencionadas, a atuação em reforço escolar está diretamente relacionada à formação docente. Essa atuação é uma contribuição social importante, no sentido de estabelecer relações entre a universidade e as instituições de educação básica da região. Tais relações aproximam o acadêmico da realidade escolar, propiciando que ele se defronte com as dificuldades que os estudantes da educação básica enfrentam para aprender matemática.

Por meio dessa aproximação com a escola de educação básica, as experiências de formação não se dão exclusivamente no âmbito da universidade, mas também na inserção no campo de trabalho. A aproximação com a educação básica atende a um dos princípios das recentes diretrizes para a formação inicial, quando se defende a necessidade de "articulação entre a teoria e a prática no processo de formação docente, fundada no domínio dos conhecimentos científicos e didáticos, contemplando a indissociabilidade entre ensino, pesquisa e extensão" (BRASIL, 2015, p. 5).

\section{AS PERCEPÇÕES DOS EGRESSOS EM RELAÇÃO A SUA FORMAÇÃO INICIAL}

Para iniciar esta reflexão, vamos apresentar alguns aspectos sobre os resultados de uma pesquisa, realizada por Gatti e Nunes (2009), sobre as características dos cursos de formação de professores. Dentre os cursos pesquisados, há indicadores sobre os cursos de licenciatura em Matemática. Ao analisar os dados, as pesquisadoras verificaram que há três tipos de cursos de licenciatura em Matemática: os que investem em formação específica em Matemática e se aproximam dos cursos de bacharelado; os que investem em formação básica de Matemática e algumas disciplinas pedagógicas; e os que oferecem formação específica de Matemática, disciplinas atribuídas à área de Educação Matemática e na área de Educação.

Com base nessa constatação pode-se afirmar que os cursos de licenciatura em Matemática estão formando profissionais com perfis diferentes. Os que têm uma formação matemática profunda talvez não se sintam preparados para enfrentar 
as situações de sala de aula, que não se restringem apenas ao saber matemático. Os licenciados com formação pedagógica desconexa da formação específica em Matemática são forçados a encontrar as inter-relações entre essas formações. Já os que têm uma formação mais aprofundada em Educação Matemática puderam participar de experiências mais contextualizadas e significativas para a construção da sua prática pedagógica (GATTI; NUNES, 2009).

Não é nossa pretensão realizar um julgamento ou classificação do curso de licenciatura de Matemática, lócus desta pesquisa, mas pensar sobre o quanto a formação para a docência deve perpassar não apenas pelos aspectos da formação específica, mas também pelas questões voltadas para a formação pedagógica. Para os egressos participantes desta pesquisa, o estágio é uma das atividades mais importantes, pois se trata de um momento em que o acadêmico vivencia o fazer docente, como observamos no seguinte excerto: "Um dos aspectos mais importantes do curso de matemática foi o Estágio Curricular Supervisionado, pois permitiu um contato com a realidade direta da sala de aula, incluindo todas as expectativas em relação à profissão" (Egresso A2). O estágio possibilita que o licenciando perceba a relação entre a teoria e a prática ao ter contato com o campo de atuação do profíssional da educação, uma vez que, "enquanto campo de conhecimento, o estágio se produz na interação dos cursos de formação com o campo social no qual se desenvolvem as práticas educativas" (PIMENTA; LIMA, 2005, p. 6).

O contato com a realidade escolar, a exemplo do estágio, envolve todas as disciplinas do curso de formação e deve acontecer durante todo o curso por meio de diferentes atividades,

[...] possibilitando que a relação entre os saberes teóricos e os saberes das práticas ocorra durante todo o percurso da formação, garantindo, inclusive, que os alunos aprimorem sua escolha de serem professores a partir do contato com as realidades de sua profissão (PIMENTA; LIMA, 2005, p. 21).

A relevância dos aspectos da prática também é mencionada nas palavras do Egresso B3: "Considero muito importante termos colocado em prática projetos desenvolvidos para serem utilizados em sala de aula nas aulas de prática de ensino. Com essas experiências, percebemos os pontos em que a prática junto com a teoria dá certo e os momentos em que não funciona tão bem. Ainda considero importantes as matérias fundamentais (matemática fundamental, álgebra, cálculo), as quais nos prepararam para que hoje tenhamos mais facilidade quando estudamos para criar as aulas". 
Para o Egresso A3, a relevância das disciplinas de formação específica é percebida na prática pedagógica, como podemos observar na fala: "Nós percebemos que, por conta daquelas disciplinas básicas, nós temos um raciocínio ou uma lógica muito mais rápida em ensinar. Então eu acho que até mesmo essas disciplinas - e não somente as disciplinas de didática - mas as disciplinas da área da Matemática Aplicada mesmo. Essas disciplinas também fizeram com que a minha prática pedagógica evoluísse. Eu acho que tudo o que eu tive refletiu na prática".

A importância do estudo dos conteúdos específicos do curso é mencionada, pois eles são fundamentais na formação da identidade da área de formação, no desenvolvimento de seu raciocínio lógico, da sua capacidade de planejar, de resolver problemas e estudar os conteúdos que são lecionados na educação básica. Conforme Tardif (2011), os saberes das disciplinas e curriculares se interligam na prática constituindo os saberes da experiência. A experiência do professor é resultado do próprio exercício da atividade profissional, representa acúmulo de conhecimento que integra o saber ensinar. $\mathrm{O}$ autor denomina os saberes da experiência os que são produzidos pelos docentes por meio da vivência de situações específicas relacionadas ao espaço da escola. Os conhecimentos adquiridos, tanto na formação inicial como na atividade docente, constituem a identidade do professor. Um curso de licenciatura precisa considerar esses conhecimentos ao organizar o seu currículo.

O saber docente é compreendido como "um saber plural, formado pelo amálgama, mais ou menos coerente, de saberes oriundos da formação profissional e de saberes disciplinares, curriculares e experienciais" (TARDIF, 2011, p. 36). Ele afirma que o professor, em sua prática cotidiana, se apoia em sua experiência e faz uso de seus conhecimentos pessoais na construção de um saber-fazer personalizado, que dê conta de suas múltiplas atribuições.

Nessa perspectiva, os egressos percebem a importância do professor formador ter experiência na educação básica: “Quando os nossos professores da graduação estão em sala de aula, no ensino médio ou fundamental, com certeza o ensino fica mais perto da realidade" (Egresso B3). "Todos os professores em geral foram importantes para o crescimento pessoal e profissional durante o curso. Percebi que os professores que ainda atuam em sala de aula (ensino fundamental e médio) possuem maior facilidade na troca de experiências com os acadêmicos, pois convivem diariamente com esse cenário" (Egresso A2). 
Para que o licenciando desenvolva os conhecimentos pedagógicos, o professor formador, especialmente das disciplinas voltadas à prática docente, precisa ter vivência na escola de educação básica. Isso porque:

o conhecimento sobre o campo de trabalho, no qual os estudantes irão atuar, auxilia na contextualização dos conteúdos a serem abordados nas aulas. A experiência em escolas de Educação Básica constitui os saberes experienciais desses professores, o que pode ajudar na proposição dos conteúdos estudados na formação inicial (VOIGT; PESCE; GARCIA, 2016, p. 541).

Além da experiência necessária em escolas de educação básica, há outro aspecto que deve ser considerado entre os professores formadores num curso de licenciatura em Matemática: matemáticos e educadores matemáticos. Embora tenham em comum a matemática, suas práticas profissionais são distintas e seus conhecimentos não pertencem à mesma vertente epistemológica. Mesmo que sejam professores, o olhar para a matemática é diferente, assim como o olhar para os conhecimentos pedagógicos indispensáveis para saber ensinar.

Ao atuar como professor de matemática, o matemático, por conceber a matemática como um fim em si mesma, tende a promover uma educação para a matemática, priorizando conteúdos formais e incentivando a formação de pesquisadores em matemática. Já o educador matemático, por considerar a matemática como um meio ou instrumento importante para a formação intelectual do estudante, tenta promover uma educação pela matemática, colocando-a a serviço da educação (FIORENTINI; LORENZATO, 2006).

A disciplina Prática de Ensino da Matemática e o Estágio Curricular Supervisionado são reconhecidos pelos participantes como fundamentais para a sua constituição como professores. A oportunidade de realizar e estudar as práticas de ensino e aprendizagem por meio de atividades como o planejamento de aula, a aplicação e discussão de aulas simuladas, construção de materiais didáticos, estudos de caso, uso de jogos é destacada nas seguintes falas: “Aulas em que podíamos fazer esse 'treino', onde éramos desafiados a criar um planejamento e a executá-lo. E depois a participar das aulas dos colegas de sala, em que podíamos verificar se o planejamento alcançou ou não [o objetivo]" (Egresso B3); "O aspecto de maior relevância no curso de Licenciatura de Matemática com certeza foi o Estágio. Ele é um elo de ligação entre toda a teoria vista no decorrer do curso e a vontade de ser professor. Não podendo deixar de citar também outras contribuições do curso para a minha prática em sala 
de aula, tais como: o estudo feito de várias metodologias utilizadas para o ensino e aprendizagem da matemática (resolução de problemas, etnomatemática, modelagem matemática, história da matemática, o uso das tecnologias...), os planos de aulas desenvolvidos, todas as leituras de livros, artigos, reportagens, seminários, palestras, cursos, congressos, entre outros" (Egresso A1).

Os aspectos apontados pelos egressos são corroborados pela ideia de Nóvoa (2009), ao afirmar que a formação de professores deve assumir uma forte componente "práxica", centrada nos alunos e nos estudos de casos concretos, tendo como referência o trabalho escolar.

Nóvoa (2009) apresenta quatro recomendações importantes para a formação docente. A primeira é o trabalho com casos concretos de ensino de insucesso escolar, problemas escolares ou programas de ação educativa, que podem ser resolvidos por meio da análise e mobilização de conhecimentos teóricos. A segunda, a importância de um conhecimento que vai para além da "teoria" e da "prática" e que reflete sobre o processo histórico da sua constituição, o papel dos indivíduos e contextos. A terceira, a procura de um conhecimento pertinente, que não é uma mera aplicação prática de qualquer teoria, mas que exige sempre um esforço de reelaboração. A quarta consiste na importância de conceber a formação de professores num contexto de responsabilidade profissional e que seja dada uma atenção constante à necessidade de mudanças nas rotinas de trabalho, pessoais, coletivas ou organizacionais.

O fazer docente também se constitui nas relações interpessoais. As vivências com professores e colegas de curso favorecem a superação de dificuldades, pois especificamente o estudo da matemática requer o desenvolvimento do raciocínio lógico, da abstração, e muitas vezes o acadêmico, sozinho, não consegue. " $E$ os alunos aprendem uns com os outros. Às vezes, se eu aprendi melhor um determinado conteúdo, então nós sentávamos juntos para trabalhar" (Egresso B3). Além da superação das dificuldades relacionadas às disciplinas específicas do curso, os egressos manifestaram aprender sobre a prática pedagógica com a experiência de seus colegas: "Outros colegas contam experiências, por exemplo: 'Eu já dei aula lá'. E conta a experiência de trabalho dele" (Egresso B3); “Troca de ideias e troca de valores. Isso é o fundamental. Cada um que já tinha trabalhado, cada um que começou trabalhar, aquela troca de ideias sobre o que já foi feito, sobre o que você faz para melhorar" (Egresso C1).

A importância dada pelos egressos às relações interpessoais, movidas não apenas pelos momentos de troca de experiências, como também para auxiliar o outro, 
remete-nos à reflexão de Nóvoa (2009), quando diz que ser professor é ser também uma pessoa e que como tal é impossível separar as dimensões pessoais das profissionais. Dessa forma, a relação docente-aluno exige que os professores sejam pessoas inteiras, assim como os estudantes. Concordamos com Nóvoa (2009, p. 40) quando afirma:

A formação deve contribuir para criar nos futuros professores hábitos de reflexão e de auto-reflexão que são essenciais numa profissão que não se esgota em matrizes científicas ou mesmo pedagógicas, e que se define, inevitavelmente, a partir de referências pessoais.

Dos aspectos que caracterizam o bom professor, Nóvoa (2009) também destaca a importância do "tacto pedagógico", quando se refere à capacidade do professor de se relacionar no ato de educar, de ter a serenidade de quem é capaz de se dar ao respeito, conquistando seus alunos nas situações de ensino-aprendizagem. E isso está diretamente relacionado às dimensões pessoais do professor. Assumindo o processo de ensino e aprendizagem como social e destacando a importância do outro (nesse caso, o professor) tanto na construção do conhecimento quanto na constituição do próprio sujeito, concordamos com o seguinte pensamento de Tassoni (2000, p. 13):

O que se diz, como se diz, em que momento e por quê; da mesma forma que, o que se faz, como se faz, em que momento e por quê, afetam profundamente as relações professor-aluno, influenciando diretamente o processo de ensino-aprendizagem. O comportamento do professor, em sala de aula, expressa suas intenções, crenças, seus valores, sentimentos, desejos, que afetam cada aluno individualmente.

De acordo com Tassoni (2000), as emoções e sentimentos estão presentes nas relações. Por isso, os egressos destacaram a importância da afetividade na relação professor-aluno, quando manifestaram que o professor importante para a sua formação profissional foi aquele que, por meio de suas ações, deu segurança aos alunos e foi humilde para aprender com eles, ou ainda "dispensou a atenção na hora de corrigir minhas redações e dar apoio necessário" (Egresso A2) e "o professor que mais me inspirou a estudar" (Egresso B3).

Para Tardif (2011), os saberes necessários ao exercício da docência são desenvolvidos no cotidiano da escola num processo coletivo de trocas de experiências. Portanto, por causa da natureza do trabalho docente, que é tanto individual quando social, faz-se necessário considerar a importância dos aspectos relacionais para que o professor possa ressignificar sua prática pedagógica.

Além do que já foi exposto, vale ressaltar que, quando o estudante de licenciatura entra em contato com as práticas ao longo do seu processo de formação, 
ele tem melhores condições de vivenciar experiências mais contextualizadas e significativas para a construção da sua prática pedagógica. Concordamos com Fiorentini (2008, p. 49):

[...] se queremos formar professores capazes de produzir e avançar os conhecimentos curriculares e de transformar a prática/cultura escolar, então é preciso que adquiram uma formação inicial que lhes proporcione uma sólida base teórico-científica relativa ao seu campo de atuação e que a mesma seja desenvolvida apoiada na reflexão e na investigação sobre a prática. Isso requer tempo relativamente longo de estudo e desenvolvimento de uma prática de socialização profissional e iniciação à docência acompanhada de muita reflexão e investigação, tendo a orientação ou supervisão de formadores-pesquisadores qualificados.

A colocação do autor reforça pressupostos de que a formação inicial deve oferecer uma sólida formação teórico-científica relacionada ao seu campo de atuação, e isso passa não somente pelos conteúdos da matemática, como também pelo referencial teórico da formação de professores e da Educação Matemática.

Percebemos em algumas das manifestações dos egressos, ao falarem sobre as dificuldades que encontram em sua prática, que a formação inicial deveria inseri-los no campo de trabalho desde o início do curso: "O aluno de qualquer licenciatura necessita estar diretamente vinculado ao meio escolar desde o primeiro semestre do curso" (Egresso C2). Hoje a realidade dos cursos de licenciatura mudou, e há políticas que permitem maior aproximação entre instituição formadora e escola de educação básica, por exemplo, por meio do Programa Institucional de Bolsas de Iniciação à Docência (PIBID). O PIBID, instituído pela Portaria Normativa n. ${ }^{\circ}$ 16, de 23 de dezembro de 2009 (CAPES, 2009), regulariza a concessão de bolsas para alunos de cursos presenciais de licenciatura que se dedicam ao estágio nas escolas públicas, para professores formadores e para professores da escola pública. Dessa forma, a construção dos saberes para a docência não se dá exclusivamente no âmbito da universidade, mas também por meio das experiências da inserção no campo de trabalho, antes mesmo da realização do estágio curricular obrigatório.

\section{CONSIDERAÇÕES}

Esta pesquisa nos permitiu apreender as percepções de professores egressos de um curso de Licenciatura em Matemática em relação à sua formação docente inicial. De acordo com os dados da investigação, as condições institucionais durante 
a formação são significativas para o desempenho e a formação do licenciado, principalmente em relação às atividades acadêmico-científico-culturais, pois a formação inicial não deve estar unicamente centrada nas disciplinas da matriz curricular; precisa ser também elemento promotor de novas relações na prática de formação. As atividades acadêmicas de iniciação científica, de projetos de extensão, grupos de estudo podem ter contribuído para o bom desempenho desses egressos no curso, por isso devem ser incentivadas pelas políticas acadêmicas.

Além de reconhecerem a importância do estudo dos conteúdos específicos da Matemática, os egressos destacam que os conteúdos das disciplinas pedagógicas foram importantes na sua formação. Esse resultado mostra que a profissionalização do professor, nesse caso, da educação básica passa pelo reconhecimento da importância dos saberes necessários da função de ensinar.

Os participantes da pesquisa ressaltaram que o estágio representou uma oportunidade de articulação entre a dimensão teórica e a dimensão prática do curso de formação, ambas indispensáveis à formação do futuro professor. Então, a instituição de ensino superior, por meio de políticas adequadas, deveria proporcionar maior aproximação e integração entre os cursos de formação inicial e os campos de estágio, com o objetivo de contribuir com a prática dos futuros professores e a dos professores supervisores no campo de estágio. Políticas como a do PIBID são muito importantes para a formação docente. Desde a sua implantação em 2009, tem aproximado as instituições de ensino superior e as de educação básica e promovido formação para os licenciandos, bem como promovido o desenvolvimento profissional dos professores que atuam nas escolas.

Os resultados da pesquisa também indicaram que os relatos das experiências dos colegas e professores na educação básica e as práticas de ensino vivenciadas ao longo do curso foram significativos para o processo de formação. Porém há que se questionar se as experiências mencionadas pelos formadores e colegas foram de fato utilizadas de forma a produzir uma reflexão teórica. Será que as condições históricas e sociais dos sujeitos envolvidos foram consideradas ao desenvolver as práticas de ensino e aprendizagem? Será que depreenderam os elementos teóricos das experiências vividas no curso? Concordamos com Zeichner (2003): “muitas vezes a reflexão sobre a prática é feita de forma individual sem ênfase numa prática social. Assim o professor passa a ver os problemas apenas como seus sem relação com os demais e com as estruturas e sistemas escolares". 
Ao ouvir os egressos a pesquisa permite pensar não somente o curso de Matemática, mas os demais cursos de formação de professores. A relação entre o aporte teórico e as respostas dos egressos ao questionário proposto permitiu uma breve reflexão sobre os cursos de formação de professores, especialmente os de Matemática, ao refletir sobre processos, realidades, categorias ou mesmo reforçar análises já existentes. Nesse processo de pesquisa, a teorização comporta "[...] manter a crítica como norte e como companheira nesse caminho de investigar transformando, transformar na investigação, compreender para transformar" (AGUIAR et al., 2009, p. 70).

\section{REFERÊNCIAS}

AGUIAR, Wanda Maria Junqueira et al. Reflexões sobre sentido e significado. In: BOCK, Ana M. B.; GONÇALVES, Maria da Graça M. (Orgs.). A dimensão subjetiva da realidade: uma leitura sócio-histórica. São Paulo: Cortez, 2009.

ANDRÉ, Marli Elisa Dalmazo Afonso de. Formação de professores: a constituição de um campo de estudos. Educação, Porto Alegre, v. 33, n. 3, p. 174-181, set./dez. 2010.

BRASIL. Conselho Nacional de Educação. Resolução CNE/CP n. ${ }^{\circ}$ 01/2002, de 18 de fevereiro de 2002a. Institui as Diretrizes Curriculares Nacionais para a Formação de Professores da Educação Básica, em nível superior, curso de licenciatura, de graduação plena. Disponível em: www.planalto.gov.br. Acesso em: 18 mai. 2018.

Conselho Nacional de Educação. Resolução CNE/CP n. ${ }^{\circ}$ 02/2002. Diário Oficial da União, Brasília, seção 1, p. 8, 19 fev. 2002 b.

Conselho Nacional de Educação. Resolução CNE/CP n. ${ }^{\circ}$ 02/2015, de $1 .^{\circ}$ de julho de 2015. Define as Diretrizes Curriculares Nacionais para a formação inicial em nível superior (cursos de licenciatura, cursos de formação pedagógica para graduados e cursos de segunda licenciatura) e para a formação continuada. Diário Oficial [da] República Federativa do Brasil, Brasília, seção 1, n. 124, p. 8-12, 2 jul. 2015. Disponível em: http://pesquisa.in.gov.br/imprensa/jsp/visualiza/index.jsp?data=02/07/2015\&jornal=1\&pa gina $=8 \&$ totalArquivos=72. Acesso em: 18 mai. 2018.

CAPES - COORDENAÇÃO DE APERFEIÇOAMENTO DE PESSOAL DE NÍVEL SUPERIOR. Portaria Normativa n. ${ }^{\circ}$ 16, de 23 de dezembro de 2009. Programa Institucional de Bolsas de Iniciação à Docência. 2009. Disponível em: http://www.capes.gov.br/images/stories/download/bolsas/Portaria16_241209.pdf. Acesso em: 18 mai. 2018.

FIORENTINI, Dario. A pesquisa e as práticas de formação de professores de Matemática em face das políticas públicas no Brasil. Bolema, Rio Claro, ano 21, n. 29, p. 43-70, 2008.

; LORENZATO, Sergio. Investigação em educação matemática: percursos teóricos e metodológicos. Campinas: Autores Associados, 2006.

GATTI, Bernadete Angelina; NUNES, Marina Muniz R. (Orgs.). Formação de professores para o ensino fundamental: estudo de currículos das licenciaturas em pedagogia, língua portuguesa, matemática e ciências biológicas. São Paulo: FCC/DPE, 2009. 
GONZÁleZ REY, Fernando. Pesquisa qualitativa e subjetividade: os processos de construção da informação. São Paulo: Pioneira Thomson Learning, 2005.

HARGREAVES, Andy. $O$ ensino na sociedade do conhecimento: a educação na era da insegurança. Porto: Porto, 2003.

IMBERNÓN, Francisco. Una nueva formación permanente del profesorado para um nuevo desarollo profesional y colectivo. Revista Brasileira de Formação de Professores, v. 1, n. 1, p. 31-42, maio 2009.

LÜDKE, Menga; ANDRÉ, Marli Elisa Dalmazo Afonso de. Pesquisa em educação: abordagens qualitativas. São Paulo: EPU, 1986.

MARCELO, Carlos. Desenvolvimento profissional docente: passado e futuro. Sisifo Revista de Ciência da Educação, n. 8, p. 7-22, jan./abr. 2009. Disponível em: http://www.fep.porto.ucp.pt/sites/default/files/files/FEP/SAME/docs/Carlosmarcelo_ Desenv_Profissional.pdf. Acesso em: 01 jun. 2018.

MOREIRA, Plinio Cavalcanti et al. Quem quer ser professor de Matemática? Zetetiké, v. 20, n. 37, jan./jun. 2012. Disponível em: http://www.repositorio.ufop.br/bitstream/ 123456789/4595/1/ARTIGO_QuemQuerSer.pdf. Acesso em: 20 out. 2017.

NÓVOA, Antônio. Professores: imagens do futuro presente. Lisboa: Relgráfica Artes Gráficas, 2009.

PIMENTA, Selma Garrido; LIMA, Maria Socorro Lucena. Estágio e docência: diferentes concepções. Revista Poiésis, v. 3, n. 3, p. 5-24, 2005.

ROLDÃO, Maria do Céu. Profissionalidade docente em análise - especificidades dos ensinos superior e não superior. Revista Nuances, jun. 2006.

TARDIF, Maurice. Saberes docentes e formação profissional. 12. ed. Petrópolis: Vozes, 2011.

TASSONI, Elvira Cristina Martins. Afetividade e aprendizagem: a relação professoraluno. In: REUNIÃO ANUAL DA ANPED. 2000. Disponível em: http://www.puccampinas.edu.br/cca/producao/arquivos/extensao/Afetividade_aprendizagem.PDF.

Acesso em: 14 jul. 2011.

VOIGT, Jane Mery Richter; PESCE, Marly Krüger; GARCIA, Berenice Rocha Zabbot. Contribuições de uma proposta integradora em cursos de licenciatura: a visão dos professores formadores. Atos de Pesquisa em Educação, v. 11, n. 2, p. 532-548, 2016.

ZEICHNER, Kenneth M. Formando professores reflexivos para a educação centrada no aluno: possibilidades e contradições. In: BARBOSA, Raquel Lazzari Leite (Org.). Formação de educadores: desafios e perspectivas. São Paulo: Editora Unesp, 2003. p. 35-55. 